\title{
O dever fundamental de proteção ao meio ambiente do trabalho saudável
}

\section{The health labor environment protection as a fundamental duty}

\author{
Gabriela Schneider ${ }^{1}$ \\ Vitor Siqueira ${ }^{2}$ \\ Daury César Fabriz 3
}

\begin{abstract}
Resumo: Com a Constituição da República de 1988, o Direito Ambiental atinge novo patamar. Quando o artigo 225, da CR88, preceitua o direito de todos ao meio ambiente ecologicamente equilibrado, abre espaço para uma proteção ampliada: do meio ambiente natural ao meio ambiente artificial, o qual alcança o meio ambiente cultural e do trabalho. É sobre este último que o presente trabalho pretende se debruçar: o direito ao meio ambiente do trabalho saudável exige uma efetiva sistemática, da qual decorre o necessário reconhecimento do meio ambiente de trabalho como um dever, indispensável para a efetivação deste enquanto direito fundamental. Assim, o presente estudo indaga: a proteção ao meio ambiente de trabalho saudável é, para além de um direito, um dever fundamental a ser preservado não só pelo Estado como também por todos os particulares? Para responder a esta indagação, introduziremos, no primeiro capítulo, a temática dos deveres fundamentais, no segundo capítulo abordaremos o direito ao meio ambiente de trabalho saudável e, finalmente, no terceiro capítulo, construiremos o meio ambiente laboral equilibrado como dever fundamental.
\end{abstract}

Palavras-chave: direito fundamental; dever fundamental; meio ambiente do trabalho saudável.

\begin{abstract}
With the 1988's Constitution, the Environmental Law reaches a new level. When article 225 of 88 's Constitution provides for everyone the right of an ecologically balanced environment, it opens up space for an extended protection: from the natural environment to the artificial environment, which reaches the cultural and the labor environment. The present work intends to study the last one: the right to healthy working environment requires an effective systematic, which results in the
\end{abstract}

\footnotetext{
1 Mestranda do Programa de Pós-Graduação Stricto Sensu em Direitos e Garantias Fundamentais da Faculdade de Direito de Vitória (FDV). Membro do Grupo de Pesquisa "Estado, Democracia Constitucional e Direitos Fundamentais" da FDV. Advogada.

2 Mestrando do Programa de Pós-Graduação Stricto Sensu em Direitos e Garantias Fundamentais da Faculdade de Direito de Vitória (FDV). Membro do Grupo de Pesquisa "Invisibilidade Social e Energias Emancipatórias em Direitos Humanos" da FDV. Advogado.

${ }^{3}$ Doutor e Mestre em Direito pela Universidade Federal de Minas Gerais - UFMG. Professor do Programa de Pós-Graduação Stricto Sensu em Direitos e Garantias Fundamentais da Faculdade de Direito de Vitória (FDV). Coordenador do Grupo de Pesquisa "Estado, Democracia Constitucional e Direitos Fundamentais". Graduado em Direito pela Universidade Federal do Espírito Santo (UFES). Graduado em Ciências Sociais pela UFES. Advogado.
} 
necessary recognition of the working environment as a duty, indispensable for effectiveness of this as a fundamental right. Thus, the present study intends to answer the question: is health labor environment protection, beyond a right, also a fundamental duty that needs to be preserved by the State but also by all the citizens? To answer the question, we will introduce, in the first chapter, the theme of fundamental duty. In the second chapter, we will discourse the health work environment right and, finally, in the third chapter, will be build the balanced work environment as a fundamental duty.

Keywords: fundamental right; fundamental duty; health work environment.

\section{Introdução}

O Direito Ambiental foi amplamente resguardado no Ordenamento Jurídico brasileiro que, no artigo 225, da Constituição da República de 1988, preceitua o direito de todos ao meio ambiente ecologicamente equilibrado. A proteção do meio ambiente foi alargada com a CR88, alcançando desde o meio ambiente natural ao meio ambiente artificial, no qual se insere o meio ambiente cultural e do trabalho. Com este último, tem lugar um novo paradigma, do qual decorre a necessidade de uma efetiva sistemática para tutelar o direito ao meio ambiente de trabalho saudável. Ocorre que este direito não se efetiva desvinculado ao seu dever correlato. Assim, se por um lado tem-se o direito ao meio ambiente de trabalho saudável, por outro lado, nota-se que a sua efetivação está adstrita ao dever de proteger o meio ambiente de trabalho, tornando-o ou conservando-o saudável.

Todavia, o debate em torno dos deveres fundamentais foi, por muito tempo, um tanto esquecido nas academias e instituições jurídicas, o que se deve, além de outros fatores, ao temor gerado pelas atrocidades que marcaram a Segunda Grande Guerra, bem como ao retorno de uma visão liberal acerca dos direitos fundamentais. Assim foi que, por muito tempo, os deveres fundamentais foram analisados sob uma ótica liberal que, preocupada com o reconhecimento de direitos - especialmente os chamados negativos - se esqueceu da responsabilidade solidária e comunitária dos indivíduos. Por outro lado, porém, a perspectiva comunitarista que marcou 
os regimes totalitários e autoritários europeus do século XX inibiu ainda mais a tentativa de debate acerca do tema dos deveres. De todo modo, acredita-se que atualmente há espaço para o ressurgimento de trabalhos e debates em torno dos deveres fundamentais, os quais devem ser reconhecidos, com base na solidariedade, para a própria garantia dos direitos fundamentais.

Em decorrência disso, o presente trabalho visa responder a seguinte indagação: a proteção ao meio ambiente de trabalho saudável é, para além de um direito, um dever fundamental a ser preservado não só pelo Estado como também por todos os particulares? A hipótese é de que a proteção ao meio ambiente de trabalho saudável, por força do artigo 225, CF, é não apenas um direito do trabalhador, mas também um dever que tem como destinatários o Estado e todos os particulares, não se restringindo apenas aos que integram a relação de trabalho, mas alcançando também todos os demais cidadãos que podem afetar, de alguma maneira, a salubridade do ambiente laboral. A metodologia utilizada é a dedutiva: parte-se do geral para o particular no seguinte sentido: do direito fundamental ao meio ambiente, passando pelo direito ao meio ambiente do trabalho saudável e finalmente chegando ao dever fundamental de proteção ao meio ambiente do trabalho saudável.

\section{Os deveres fundamentais}

A Declaração dos Direitos do Homem e do Cidadão, de 1789, inaugura a "Era dos Direitos", marcando a passagem da teoria à pratica, com a afirmação da concretude dos direitos humanos, que ganha sua universalidade quase dois séculos mais tarde, com a Declaração Universal dos Direitos do Homem, aprovada por 48 Estados, em 1948, na Assembleia Geral das Nações Unidas (BOBBIO, 2004), no cenário pós Segunda Guerra mundial. 
A partir de então, o mundo experimentou um período em que apenas se falava da liberdade e dos direitos que a concretizam, dispensando-se especial dedicação constitucional e doutrinária aos direitos fundamentais (NABAIS, p. 02-04). Com isso, não se quer afirmar que a atenção destinada ao tema dos direitos seja indevida, mas apenas demonstrar que os direitos comportam, nos termos de José Cassalta Nabais, uma face oculta, que é exatamente a dos deveres fundamentais.

Frise-se, porém, que afirmar que os direitos fundamentais comportam uma face oculta - a dos deveres fundamentais -, não importa declarar que estes seriam reflexos dos direitos fundamentais, pois há certa desvinculação entre direitos e deveres, sendo que os últimos também merecem ser tratados como categoria autônoma.

Fato é que os diretos fundamentais sempre tiveram posição de destaque, enquanto os deveres em geral e os deveres fundamentais em particular foram objeto de um pacto de silêncio, cuja causa pode ser atribuída à conjuntura política, social e cultural do segundo pós-guerra, bem como à retomada de uma visão liberal dos direitos fundamentais (NABAIS, p. 02-04).

Os deveres fundamentais, contudo, não podem ser analisados nem a partir da perspectiva do liberalismo, que reconhecia apenas direitos e esquecia a responsabilidade comunitária dos indivíduos, nem tampouco a partir da perspectiva do comunitarismo, que só conhece funções, como foi o caso dos regimes totalitários e autoritários que marcaram a história da Europa no século XX.

Basso (2016, p. 92) esclarece que os deveres fundamentais são elementares na realização da dignidade da pessoa humana, de modo que ficar adstrito apenas ao atendimento dos direitos fundamentais, oponíveis contra o Estado, não seria suficiente. Os indivíduos, para que desfrutem de sua intrínseca dignidade precisam cumprir deveres para com o corpo social. Neste diapasão, Siqueira (2010, p. 215) aduz que "não se pode, atualmente, 
conceber o indivíduo como portador apenas de direitos, devendo-se observálo também como sujeito de deveres (...)". Desse modo, os deveres fundamentais constituem categoria autônoma, mas, por serem importantes para a própria preservação dos direitos fundamentais, integram o domínio destes. Por esta razão, historicamente se formaram tantas camadas de deveres quanto as camadas de direito (NABAIS, p 05).

Nabais adverte que os primeiros deveres fundamentais, previstos nas primeiras constituições liberais, foram o de defesa da pátria e o de pagar impostos, advindo, posteriormente, o dever de votar e, sucessivamente, os deveres sociais, conduzidos pela Constituição do México de 1917 e de Weimer, de 1919. Por fim, a geração posterior de deveres associa-se ao patrimônio cultural e ao meio ambiente, os também denominados "deveres de solidariedade". Temos, assim, os deveres advindos da época liberal - de defesa à pátria e de pagar impostos -; os resultantes da revolução democrática - materializados na conquista do sufrágio universal, atrelados aos deveres pilares do estado social, isto é, aos deveres econômicos e sociais -; e uma última camada, constituída pelos deveres ecológicos e culturais (NABAIS, p 06).

Embora tenha sido apresentada a (des)vinculação entre deveres e direitos fundamentais, bem como a geração histórica daqueles, ainda não foi exposta uma conceituação de dever fundamental. Assim, para melhor elucidação do tema, trazemos o conceito a ser adotado no presente trabalho, firmado pelo Grupo de Pesquisa "Estado, Democracia Constitucional e Direitos Fundamentais":

Dever fundamental é uma categoria jurídico-constitucional, fundada na solidariedade, que impõe condutas proporcionais àqueles submetidos a uma determinada ordem democrática, passíveis ou não de sanção, com a finalidade de promoção de direitos fundamentais ${ }^{4}$.

${ }^{4}$ Conceito cunhado coletivamente pelos membros do Grupo de Pesquisa "Estado, Democracia Constitucional e Direitos Fundamentais", coordenado pelos professores Adriano Sant'Ana Pedra e Daury Cesar Fabriz, do Programa de Pós-Graduação 
O primeiro elemento que compõe o conceito de dever fundamental é a solidariedade, cuja previsão constitucional está especialmente detalhada no artigo $3^{\circ}$, incisos I e IV, por meio dos quais se aduz que constituem objetivos fundamentais da República Federativa do Brasil construir uma sociedade solidária e promover o bem de todos. A previsão constitucional demonstra que a solidariedade e, por consequência, o cumprimento de um dever fundamental não resulta, necessariamente, do altruísmo das pessoas, sendo decorrência do próprio ordenamento vigente no Brasil. Conforme dispõem Abreu e Fabriz (2014, p. 6):

\begin{abstract}
A solidariedade reflete a corresponsabilização de todos os indivíduos pelos problemas sociais e pela solução desses problemas. Os cidadãos são mutuamente detentores de direitos e de deveres perante a comunidade e aos demais cidadãos. O binômio direitodever expressa a relação solidária no Estado Democrático de Direito.
\end{abstract}

A imposição de "condutas proporcionais àqueles que estão submetidos a determinada ordem democrática" é outro elemento que compõe o conceito de "dever fundamental" e significa que o esforço a ser imposto na realização do dever não pode ser exorbitante. A este respeito, Pedra (2013, p. 287-288) salienta que "mesmo em decorrência da ideia de solidariedade não se pode impor ao sujeito do dever um sacrifício extraordinário - ou desproporcional com o fim de salvaguardar determinado direito". Assim, o ônus a ser suportado pelo sujeito do dever não pode ser excessivo, e a exorbitância deve ser analisada no caso concreto, nunca em abstrato, levando-se em consideração o objetivo que se deseja alcançar com a obrigação imposta.

Por fim, os deveres podem estar ou não submetidos a sanção. Siqueira (2016, p. 131-135) explica que deveres e obrigações são condutas estabelecidas por normas jurídicas. E a norma jurídica não possui como elemento intrínseco a sanção, sendo possível notar a existência de normas de

Stricto Sensu-Mestrado e Doutorado -em Direitos e Garantias Fundamentais da Faculdade de Direito de Vitória (FDV). 
conduta com e sem sanção. Para o autor, é a dualidade entre normas que admitem ou não sanção que permite distinguir os deveres das obrigações. $\mathrm{O}$ autor salienta que

(...) quando ao dever jurídico se contrapuser um direito subjetivo, a relação jurídica será obrigacional, já que o descumprimento do dever resultará na violação do direito (subjetivo), cuja proteção poderá ser objeto de uma pretensão e poderá ensejar na aplicação de sanção. De outro modo, quando não há contraposição, mas, sim, a existência de um poder (potestade) ou de uma faculdade (permissão), o indivíduo tem dever apenas em relação a si próprio, pois no caso de não exercê-lo, abre mão de um possível direito (subjetivo) que teria, não violando direito algum, apenas suportando um ônus que ele próprio escolheu (...).

Os deveres fundamentais podem se apresentar ou como obrigações em que a conduta é devida em virtude de um vinculo relacional - ou como deveres propriamente ditos - que supõe um valor intrínseco, sendo sempre incondicional. Destarte, a possibilidade de um dever fundamental se apresentar tanto como obrigação quanto como dever propriamente dito explica a submissão ou não à sanção.

Assim, esgotada, por ora, a análise do conceito de dever fundamental a ser adotado e, em especial, de seus elementos - solidariedade, imposição de esforço proporcional e possibilidade ou não de previsão de sanção -, vislumbra-se cenário favorável à introdução do dever a ser especificamente estudado no presente trabalho, qual seja: o dever de proteção ambiental. $\mathrm{O}$ artigo 225, da Constituição da República de 1988 dispõe que

Todos têm direito ao meio ambiente ecologicamente equilibrado, bem de uso comum do povo e essencial à sadia qualidade de vida, impondo-se ao Poder Público e à coletividade o dever de defendê-lo e preservá-lo para as presentes e futuras gerações.

O direito ao meio ambiente ecologicamente equilibrado se traduz, assim, como forma de expressão e desenvolvimento da dignidade humana, que tem como consequência patente o dever de proteção ambiental, vital à própria preservação da espécie humana que, "como ser biótico que é, integra 
o meio ambiente e depende da natureza e da salubridade de seus recursos tanto quanto os demais seres vivos, por isso o dever de proteger o ambiente faz parte de um dever maior de solidariedade, com a própria espécie e com as demais espécies" (ABREU e FABRIZ, 2014, p. 11). Sobre o direito/dever ao meio ambiente, Canotilho (2001, p. 13) se posiciona afirmando que

\begin{abstract}
Depois de uma certa euforia em torno do individualismo dos direitos fundamentais que, no nosso campo temático, se traduzia na insistência em prol da densificação de um direito fundamental ao ambiente, fala-se hoje de um comunitarismo ambiental ou de uma comunidade com responsabilidade ambiental assente na participação activa do cidadão na defesa e proteç̧ão do meio ambiente".
\end{abstract}

Ocorre que, se a categoria jurídica dos deveres fundamentais é de modo geral um tanto esquecida, os deveres que integram a dimensão ecológica, entre eles o dever de proteção ambiental, sofre ainda maior desprestígio, já que o impacto da proteção ambiental costuma ser, por vezes, encarado como um ônus excessivo no cotidiano dos cidadãos e na economia. Soma-se a isso que, em decorrência da multiplicidade de efeitos que as normas ambientais possuem, seus reflexos são sentidos em todas as ações sociais e âmbitos da vida humana. Ademais, considerando que dois dos principais pilares de sobrevivência do ser humano são o seu habitat natural e o trabalho, a proteção ambiental tem alcançado novos espaços, não se limitando apenas aos elementos naturais do ambiente, mas abrangendo também o meio ambiente artificial, cultural e laboral.

Assim, no novo espaço alcançado pelo Direito Ambiental, também se inclui a esfera laboral, exigindo-se, dessa forma, a proteção ao meio ambiente do trabalho (PADILHA, 2002, p. 18).

\title{
3. O direito ao meio ambiente de trabalho saudável
}




\section{DIREITO}

O equilíbrio do ambiente de trabalho teve sua proteção alargada enquanto direito fundamental do ser humano em decorrência da ampla tutela jurídica conferida pela Constituição da República de 1988 ao meio ambiente, que se estende do meio ambiente natural ${ }^{5}$ ao meio ambiente artificial $^{6}$. Por consequência, há o advento de um novo paradigma de proteção ao trabalhador, exigindo-se uma sistematização da real dimensão de tutela jurídica do direito ao meio ambiente do trabalho equilibrado (PADILHA, 2010, p. 373).

O meio ambiente do trabalho, além da proteção constitucional conferida pelo artigo 225, da CR88, outrora mencionado, também se encontra salvaguardado pelos artigos 200, inciso VIII ("Ao sistema único de saúde compete, além de outras atribuições, nos termos da lei: (...) colaborar na proteção do meio ambiente, nele compreendido o do trabalho") e $7^{\circ}$, inciso XXII ("São direitos dos trabalhadores urbanos e rurais, além de outros que visem à melhoria de sua condição social: (...) redução dos riscos inerentes ao trabalho, por meio de normas de saúde, higiene e segurança").

Deveras, o Trabalho ocupa posição privilegiada no Ordenamento Jurídico brasileiro. Não por outro motivo, integra a Carta Constitucional como um dos fundamentos da República (art. 1º, CR88), tem a sua valorização como um dos fundamentos da ordem econômica (art. 170, CR88) e constitui como base da ordem social o primado do trabalho (art. 193, CR88).

No regime sistemático de proteção ao meio ambiente do trabalho, outros dispositivos legais são de importante menção. A Lei no 8.080/90 (Lei Orgânica da Saúde) trata, em diversos artigos, sobre a proteção do ambiente do trabalho e da saúde do trabalhador, que tem como determinantes e

${ }^{5}$ Segundo Fiorillo, o meio ambiente natural ou físico se constitui pela atmosfera, pelos elementos da biosfera, pelas águas, incluindo-se o mar territorial, pelo solo, pelo subsolo, pela fauna e flora (FIORILLO, Celso Antonio Pacheco. Curso de direito ambiental brasileiro. 13. ed. rev., atual. e ampl. São Paulo: Saraiva, 2012).

${ }_{6}^{6}$ Para Fiorillo, o meio ambiente artificial é constituído pelo espaço urbano construído, isto é, pelo conjunto de edificações (denominado espaço urbano fechado) e pelos equipamentos públicos (espaço urbano aberto). 
condicionantes, entre outros, "a alimentação, a moradia, o saneamento básico, o meio ambiente, o trabalho, a renda, a educação, o transporte, o lazer e o acesso aos bens e serviços essenciais" (art. $3^{\circ}$, da citada lei). A Lei $\mathrm{n}^{\circ} 8.213 / 91$ também é de imprescindível destaque, pontuando em seu artigo $19, \S 1^{\circ}$ que a empresa é responsável pela adoção e pelo uso das medidas coletivas e individuais de proteção e segurança da saúde do trabalhador.

No plano internacional, diversas normas tutelam o meio ambiente do trabalho. Dentre elas, ressalte-se as Convenções 148 de 1977, que dispõe sobre a proteção de trabalhadores contra riscos advindos da contaminação do ar, de ruídos e de vibrações que eventualmente possam existir no ambiente laboral; 155 de 1981, que prevê normas relacionadas à segurança, higiene e ao meio ambiente laborativo; e 161 de 1985, que determina diretrizes para a implementação de serviços de saúde no trabalho, todas estas editadas pela OIT - Organização Internacional do Trabalho, que cumpre papel importante na preservação do trabalho humano.

Após a breve tratativa de alguns dos dispositivos legais que versam sobre a temática, forçoso buscar uma definição para o meio ambiente de trabalho equilibrado enquanto direito fundamental. A este respeito, Fiorillo (2012, p. 81-82) inicia com a definição do meio ambiente de trabalho, aduzindo que este se caracteriza como o local onde as pessoas desempenham suas atividades laborais, remuneradas ou não, cujo equilíbrio está na salubridade do meio e na ausência de agentes que comprometam a incolumidade físico-psíquica dos trabalhadores. O autor ainda ressalva a distinção existente entre a proteção do direito do trabalho e a proteção assegurada ao meio ambiente do trabalho. A última pretende resguardar a saúde e a segurança do trabalhador no ambiente onde este desenvolve suas atividades laborais enquanto a primeira constitui o conjunto de normas jurídicas que regulam a relação jurídica entre empregado e empregador.

Em decorrência de sua íntima relação com a proteção à saúde, o equilíbrio do meio ambiente do trabalho se constitui como um direito 
essencialmente difuso, isto é, de interesse transindividual, de natureza indivisível, que tem como titulares pessoas indeterminadas (PADILHA, 2002, p. 51). Trata-se, dessa forma, de direito que transcende o indivíduo, ultrapassando o limite da esfera de direitos e obrigações de cunho individual para alcançar sua dimensão coletiva, bem como de um direito que, ao mesmo tempo que a todos pertence, ninguém especificamente o possui (FIORILLO, 2012, p. 57).

Padilha sustenta que o meio ambiente do trabalho deve garantir o exercício da atividade produtiva do indivíduo, não o considerando como um instrumento para produção de bens e serviços, mas sim como o ser humano que é, em relação ao qual devem ser preservadas bases dignas para manutenção da sadia qualidade de vida ${ }^{7}$. Deveras, a proteção constitucional ao meio ambiente traduz-se como defesa da humanização do trabalho, exigindo que o ambiente laboral seja espaço de construção de bem-estar, identidade e dignidade (PADILHA, 2002, p. 44).

Retomando a definição de ambiente de trabalho de Fiorillo exposta acima, temos que o equilíbrio a ser preservado está na salubridade do meio e na ausência de agentes que comprometam a incolumidade físico-psíquica dos trabalhadores. Assim, quando esse ambiente ou "habitat laboral"8 se revela inidôneo para resguardar as condições mínimas para a razoável qualidade de vida do trabalhador, lesa-se o meio ambiente do trabalho. Ocorre que o complexo de bens materiais e imateriais que compõem o ambiente de trabalho pode ser lesado das formas mais variadas, com fontes agressoras provenientes dos mais diversos empreendimentos. Em virtude disso, a real dimensão do direito ao meio ambiente equilibrado não se limita nem à relação obrigacional nem à barreiras físicas dos empreendimentos o que, novamente, reforça o caráter transindividual deste direito e o afasta da esfera do Direito do Trabalho para aproximá-lo do Direito Ambiental:

8Expressão utilizada por Rodolfo de Camargo Mancuso na obra "Ação Civil Pública trabalhista: análise de alguns pontos controversos". 
enquanto o Direito do Trabalho ocupa-se das relações jurídicas protagonizadas por empregado e empregador nos limites de sua relação contratual, o Direito Ambiental busca a proteção do trabalhador contra qualquer forma de degradação do ambiente em que exerce sua atividade laborativa (PADILHA, 2010, p. 376-378).

Assim, considerando que o meio ambiente do trabalho é constituído por todas as variáveis que influenciam no labor prestado pelo Homem, a sua aparente vinculação restrita ao Direito do Trabalho não se mantém. Embora a salubridade do "habitat laboral" pareça estar dependente exclusivamente da preservação de direitos assegurados aos empregados, a serem observados pelos empregadores, uma análise mais detida permite concluir que a proteção ao ambiente de trabalho saudável está vinculada à observância de normas trabalhistas não apenas pelo empregador, se estendendo até mesmo à sociedade de forma geral, vez que fatores aparentemente abstratos, como crises econômicas e desemprego tecnológico, por exemplo, também são agentes que ameaçam a saúde do trabalhador.

\section{A proteção do meio ambiente de trabalho saudável como dever}

Para retomar o estudo sobre os deveres fundamentais, após tratar do direito fundamental de proteção ao meio ambiente de trabalho saudável, importante elucidar a distinção entre deveres fundamentais em sentido amplo e em sentido estrito, bem como entre deveres autônomos e correlatos. Os deveres fundamentais em sentido amplo englobam os deveres de prestação do Estado, enquanto os deveres em sentido estrito se referem aos deveres fundamentais dos cidadãos, alcançando, portanto, os particulares (SIQUEIRA, 2010, p. 217). A distinção entre deveres autônomos e correlatos, por sua vez, pode ser percebida pela medida em que alguns deveres estão, respectivamente, menos ou mais relacionados material e diretamente à 
concretização dos direitos fundamentais (SARLET, 2009, p. 228 apud SIQUEIRA, 201, p. 218).

Ambas as classificações importam para o presente trabalho pois são primordiais para a compreensão do dever ora tratado. Isto porque, o dever fundamental de proteção ambiental na esfera laboral se subsumi tanto a classificação de um dever em sentido amplo quanto em sentido estrito, ao mesmo tempo, já que deve ser observado tanto pelo Estado quanto pelos cidadãos. Decerto, tratando-se o meio ambiente de trabalho saudável de um direito transindividual, o dever de proteger o meio ambiente de trabalho saudável também se destina a todos. Conforme exposto anteriormente, o habitat laboral saudável pode ser lesado pelos agentes mais variados: não apenas o desrespeito às normas trabalhistas pelos empregadores pode ocasionar lesões e ameaças ao ambiente de trabalho equilibrado, mas também fatores externos, como crises econômicas e desemprego tecnológico podem comprometer a saúde psíquica dos trabalhadores, o que evidencia a variedade de fontes de lesão ao direito e, consequentemente demonstra a pluralidade de destinatários do dever de proteger o ambiente laboral saudável.

Ademais, quando a Lei nº 8.080/90 (Lei Orgânica da Saúde) preceitua como determinantes e condicionantes da proteção ao ambiente de trabalho, dentre outros, "a alimentação, a moradia, o saneamento básico, o meio ambiente, o trabalho, a renda, a educação, o transporte, o lazer e o aceso aos bens e serviços essenciais" acaba por corroborar a ampliação da gama de destinatários do dever de proteção ambiental, mesclando a responsabilidade privada e púbica dos que compõem a relação laboral.

Além disso, o dever de proteção ao meio ambiente de trabalho equilibrado é inegavelmente correlato ao direito ao meio ambiente de trabalho equilibrado. A preservação deste direito é impossível sem a observância dos deveres dos mais diversos sujeitos sociais e estatais. Tanto é assim que, por vezes, até se confundem com obrigações. Para elucidar, 
trazemos os apontamentos de Garcia acerca dos deveres impostos pela Consolidação das Leis Trabalhistas (CLT) para assegurar a proteção ao meio ambiente de trabalho. $\mathrm{O}$ autor aduz que compete às Superintendências Regionais do Trabalho e Emprego promover a fiscalização do cumprimento das normas de segurança e medicina do trabalho, determinar as obras e reparos que, em qualquer local de trabalho se façam necessárias e impor as penalidades cabíveis pelo descumprimento das normas do Capítulo $\mathrm{V}$ da CLT.

As empresas, por sua vez, devem cumprir e fazer cumprir as normas de segurança e medicina do trabalho, instruir os empregados, por meio de ordens de serviço, quanto às precauções a tomar para evitar acidentes de trabalho ou doenças ocupacionais, adotar as medidas determinadas pelo órgão regional competente e facilitar o exercício da fiscalização pela autoridade competente. Por fim, cabe aos empregados observar as normas de segurança e medicina do trabalho e colaborar com a empresa na aplicação dos dispositivos do Capítulo V, do Título II, da CLT.

A partir desta exposição é possível vislumbrar, apenas com a observância de alguns deveres impostos pela CLT, que o "macro"-dever de proteção ao meio ambiente deve ser exercido, ainda que em pequenas parcelas, por atores diversos que vão do Estado à sociedade: das Superintendências Regionais do Trabalho e Emprego às empresas, passando pelos próprios empregados/trabalhadores que possuem, eles mesmos, o dever de proteção ao meio ambiente de trabalho saudável como forma de preservar o seu próprio habitat laboral.

Dessa forma, o estudo acerca do dever de proteção ambiental no âmbito laboral evidencia a insuficiência da atuação exclusiva do Estado em assegurar a efetivação do direito fundamental ao meio ambiente de trabalho saudável e democrático a que tem direito toda pessoa, sendo necessária a prestação de um dever por parte de todos, incluindo-se o Estado, os 
empregadores, os trabalhadores e, por vezes, até mesmo agentes completamente alheios à relação trabalhista.

Essa responsabilidade mútua - compartilhada entre cidadãos e Estado - apenas é possível a partir da solidariedade, elemento imanente a todo e qualquer dever fundamental, mas que é ainda mais perceptível no dever de proteção ambiental. Dito isto, resta sólido que o dever de proteção ambiental e sua fundamentalidade encontram-se asseguradas na Constituição da República, recaindo sobre todos os cidadãos, ainda que não pertencentes à relação de trabalho.

\section{Considerações Finais}

O Direito Ambiental encontra-se amplamente protegido pelo Ordenamento Jurídico brasileiro que, no artigo 225, da Constituição da República de 1988, preceitua o direito de todos ao meio ambiente ecologicamente equilibrado. A proteção do meio ambiente foi alargada com a CR88, alcançando além do meio ambiente natural, o meio ambiente artificial, no qual está inserido o meio ambiente do trabalho. Com este último, tem lugar um novo paradigma, do qual decorre a necessidade de uma efetiva sistemática para tutelar o direito ao meio ambiente de trabalho saudável.

Ocorre que a salubridade do meio ambiente de trabalho pode ter sua incolumidade violada das mais diversas formas e pelos mais variados agentes, que vão muito além de fatores atinentes apenas aos sujeitos que compõem a relação de trabalho. Isto porque, apesar de o "habitat laboral" corresponder ao local onde o trabalhador desempenha o seu labor, a saúde do trabalhador tem como determinantes e condicionantes a alimentação, a moradia, o saneamento básico, o meio ambiente, o trabalho, a renda, a educação, o transporte, o lazer e o acesso aos bens e serviços essenciais (art. 


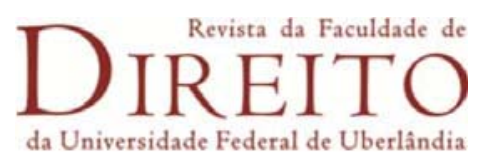

$3^{\circ}$, da Lei $\mathrm{n}^{\mathrm{o}} 8.080 / 90$ ), o que demonstra a multiplicidade de agentes que colaboram para a conservação da salubridade do ambiente laboral.

Além do mais, diversos profissionais tem um ambiente de trabalho no qual há grande movimentação de pessoas. Para exemplificar, basta citar o caso dos profissionais de limpeza urbana, cujo ambiente laboral se confunde com as próprias vias públicas. Neste sentido, qualquer transeunte pode influenciar na salubridade de seu habitat laboral sendo, desta forma, também destinatário do dever de proteção ao meio ambiente de trabalho saudável.

Com isso, é possível concluir que por força do artigo 225, da CR88, somado a dispositivos internos e internacionais de proteção ao trabalho, o meio ambiente laboral saudável é não apenas um direito, mas também um dever, a ser preservado pelo Estado, através de suas instituições de fiscalização e proteção a normas trabalhistas, mas também por toda a sociedade: pelos empregadores, pelos colegas de trabalho e pelos particulares de forma geral, ainda que não pertencentes à relação de trabalho.

\section{Referências}

ABREU, Ivy de Souza. FABRIZ, Daury César. O dever fundamental de proteção do meio ambiente e seu fundamento na solidariedade: uma análise à luz do holismo ambiental. 2014.

BASSO, Joaquim. Notas sobre o regime jurídico dos deveres fundamentais no ordenamento jurídico brasileiro. Revista DIREITO UFMS, Campo Grande, MS. V.1. n. 2. Jan./jun. 2016. Disponível em:

$<$ https://periodicos.ufms.br/index.php/revdir/article/view/769/0>. Acesso em: 02 ago. 2019.

BOBBIO, Norberto. A Era dos Direitos. Tradução Carlos Nelson Coutinho; apresentação de Celso Lafer. Nova ed. Rio de Janeiro: Elsevier, 2004. $7^{\mathrm{a}}$ reimpressão.

CANOTILHO, José Joaquim Gomes. Estado constitucional ecológico e democracia sustentada. Revista do Centro de Estudos de Direito do Ordenamento, do Urbanismo e do Ambiente. Disponível em:

$<$ https://digitalis-

dsp.uc.pt/bitstream/10316.2/5732/1/revcedoua8\%20art.\%201\%20JJGC.pdf?ln=pt-pt>.

FIORILLO, Celso Antonio Pacheco. Curso de Direito Ambiental Brasileiro. 13. ed. rev., atual. e ampl. São Paulo: Saraiva, 2012.

NABAIS, José Cassalta. A face oculta dos direitos fundamentais: os deveres e os custos dos direitos. Disponível em: 
$<$ http://www.egov.ufsc.br/portal/sites/default/files/anexos/15184-15185-1-PB.pdf $>$. Acesso em: 08 ago. 2019.

PADILHA, Norma Sueli., Do Meio Ambiente do Trabalho Equilibrado. São Paulo: LTr, 2002.

PADILHA, Norma Sueli. Fundamentos Constitucionais do Direito Ambiental Brasileiro. Rio de Janeiro: Elsevier, 2010. P. 373.

PEDRA, Adriano Santana. A importância dos deveres fundamentais. Níveis de Efetivação dos Direitos Fundamentais Civis e Sociais: um diálogo Brasil e Alemanha. Joaçaba: Editora Unoesc, 2013.

SIQUEIRA, Julio Faro Homem de. Deveres Fundamentais e a Constituição Brasileira. Revista de Filosofia do Direito, do Estado e da Sociedade, v. 1, n. 2, 2010. Disponível em: <http://www.revistafides.ufrn.br/index.php/br/article/view/41>. Acesso em: 20 jul. 2019.

SIQUEIRA, Julio Pinheiro Homem de. Elementos para uma teoria dos deveres. Revista de Direito Constitucional e Internacional. Revista dos Tribunais, Ano 24, vol. 95, abr.-jun./2016.

Artigo recebido em: 09/12/2019.

Aceito para publicação em: 09/03/2020. 